\title{
ENTRE A DOR E A SUPERAÇÃO: ADOLESCENTES COM CÂNCER DISCUTEM SUA REPRESENTAÇÃO NAS NOTÍCIAS
}

\author{
Between pain and overcoming: adolescents with cancer debate their
} representation in the news

Entre el dolor y la superación: adolescentes con cáncer discuten su representación en las noticias

Raiana de Carvalho Universidade Federal do Ceará rai.soraia@gmail.com

Inês Vitorino Sampaio Universidade Federal do Ceará inesvict@gmail.com

Lidia Marôpo

Instituto Politécnico de Setúbal/ Centro Interdisciplinar de Ciências Sociais Aplicadas (CICS.Nova) Universidade Nova de Lisboa lidiamaropo@gmail.com

\section{Resumo}

Este artigo analisa os processos de apropriação do discurso noticioso por adolescentes que estão em tratamento contra o câncer em uma instituição sem fins lucrativos em Fortaleza, Ceará, tomando os estudos culturais e a pesquisa latinoamericana como referencial teórico. O objetivo é compreender como eles analisam as suas representações nas notícias e o seu lugar no processo de produção destas. Com base em dois grupos de foco, oito participantes revelam preocupações com a vitimização dos doentes e o desejo de enquadramentos mais otimistas, que os valorizem como sujeitos participantes das notícias em seus próprios termos e condições.

Palavras-chave: Processos de apropriação. Notícias. Adolescentes com câncer.

\section{Abstract}

This article analyzes the appropriation processes of teenagers on the news about adolescents who are being treated against this disease in a non-profit institution, in Fortaleza, Brazil. The article is based on the theoretical framework of Cultural Studies and Latin American research

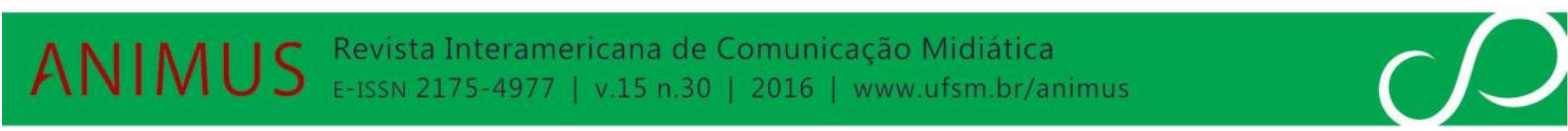


and aims at to understanding how these teens evaluate their representations in the news and their place in this news production process. For that, two focus groups have been conducted. In those groups, eight participants revealed concerns on the victimization of patients and the desire that journalism presents more optimistic frameworks which value them as subjects participants of the news on their own terms and conditions.

Key words: Appropriation processes. News. Adolescents with cáncer.

\section{Resumen}

Este artículo analiza los procesos de apropiación del discurso periodístico por adolescentes que están en tratamiento clínico contra el cáncer en una institución sin fines lucrativos en Fortaleza, Ceará, tomando los estudios culturales y la investigación latinoamericana como referencia teórica. Estos analizan sus representaciones en las noticias y su lugar en el proceso de producción de las mismas. A partir de dos grupos analizados, ocho participantes revelan preocupaciones con la victimización de los enfermos y el deseo de perspectivas más optimistas que los valoren como sujetos participantes de las noticias en sus propios términos y condiciones.

Palabras clave: Procesos de apropiación. Noticias. Adolescentes con cáncer.

\section{INTRODUÇÃO}

No contexto cearense, crianças e adolescentes com câncer são pautas frequentes do discurso noticioso, especialmente em datas comemorativas, como o Dia Nacional do Voluntariado (agosto), o Dia das Crianças (outubro), o Dia Nacional do Combate ao Câncer Infantojuvenil (novembro) e a campanha McDia Feliz. Esta cobertura jornalística pode promover sentimentos como os de empatia ou solidariedade e favorecer o reconhecimento social da doença, permitindo angariar mais doações, parcerias e trabalho voluntário para o tratamento em instituições públicas ou da sociedade civil. Por outro lado, a maneira como meninos e meninas são enquadrados e identificados no discurso noticioso pode causar constrangimentos e restringir a sua representação ao papel de vítimas, cuja condição precípua é a de passividade diante do sofrimento e da própria vida.

Como o agendamento e o enquadramento midiático dos acontecimentos e problemáticas influenciam significativamente nas imagens que as pessoas fazem delas mesmas, dos outros, das suas necessidades, dos seus objetivos e das suas relações com os outros (PATTERSON in CORREIA, 2004, p. 33), as notícias têm impacto significativo na imagem social e, consequentemente, na vivência de crianças e adolescentes com câncer. Estas se constituem num poderoso promotor de mapas de significado (HALL et al, 1978), classificando o mundo e

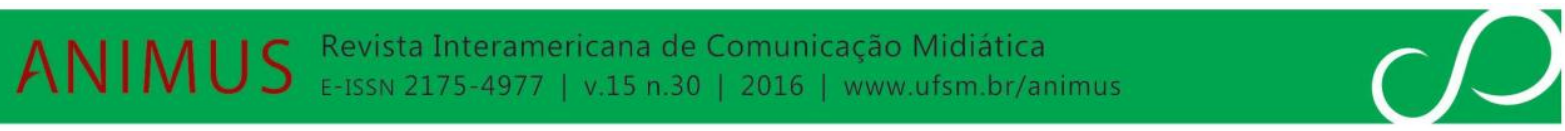


construindo lugares a partir de onde meninos e meninas podem se posicionar e falar (WOODWARD, 1997: 14).

O objetivo deste artigo é compreender os processos de apropriação do discurso noticioso por jovens que estão em tratamento contra o câncer. Queremos conhecer os seus pontos de vista, identificando-os como fundamentais para uma reflexão sobre as suas representações nas notícias e para pensarmos sobre como avaliam o seu lugar no processo de produção destas.

Neste sentido, chamamos a atenção para os depoimentos de crianças e jovens que, em inúmeros estudos, alertam para situações problemáticas relativas à sua representação no discurso noticioso: a estigmatização da pobreza e de minorias étnicas, a preservação da identidade e as consequências da exposição pública em situações que possam causar constrangimentos, a estereotipação das crianças como vítimas indefesas e dos jovens como problemáticos e a escassez das suas vozes nas notícias (AL-GHABBAN, 2007; ANDI, 2008; CARVALHO E SERRÃO, 2009; DELORME, 2012; FISCHBERG, 2007; MARÔPO e GOMES, 2014; MARÔPO, 2014; ALON-TIROSH e LEMISH, 2014; BRITES, 2015).

Crianças e adolescentes em situação de risco, de minorias étnicas, de bairros periféricos ou com deficiências físicas são referidos nestas pesquisas que reconhecem a capacidade de reflexão destes acerca das notícias. No entanto, a representação de crianças e adolescentes com câncer (ou outras doenças graves) nas notícias, ou a sua perspectiva sobre estas, não têm despertado o interesse de estudos acadêmicos. Neste sentido, ressaltamos o ineditismo do tema aqui estudado como uma oportunidade para debatermos questões sensíveis sobre a noticiabilidade deste grupo.

Para discutir essa problemática, utilizamos metodologias qualitativas que incluem visitas de observação à uma instituição do terceiro setor especializada no tratamento do câncer infantojuvenil em Fortaleza; a aplicação de um questionário de identificação dos participantes da pesquisa (com questões relacionadas à idade, escolaridade, profissão dos pais e sobre o acesso a notícias e aos meios de comunicação) e a realização de dois grupos focais com um total de oito participantes.

O trabalho de campo que desenvolvemos parte da premissa central de que crianças e adolescentes são sujeitos capazes de construir sentidos sobre os conteúdos midiáticos com os quais se relacionam, não se configurando, portanto, como meros receptores passivos. Tomamos como referencial teórico as pesquisas latinoamericanas que ressaltam a assimetria entre os processos de produção e de recepção, constatando a impossibilidade da existência de 
interpretações "únicas” ou “corretas” dos conteúdos dos media (MARTÍN-BARBERO, 1995 e CANCLINI, 2008). Consideramos como fundamentais as reflexões dos Estudos Culturais que "procuram entender as práticas de mídia das crianças em seus próprios termos e a partir das suas próprias perspectivas" (BUCKINGHAM, 2012, p. 96). Buscamos pensar os meios de comunicação em relação aos contextos sociais práticos nos quais os indivíduos se apropriam das formas simbólicas mediadas, adaptando-as às suas vidas e contextos (THOMPSON, 2007, p. 45). Nosso propósito é o de reconhecer os jovens como cidadãos, nos termos de Dahlgren (2009), que enfatiza a ação como condição fundamental para que eles construam a sua identidade cívica.

Nesta perspectiva, os participantes deste estudo analisam criticamente a representação noticiosa de crianças e adolescentes com cancro nas notícias e sugerem enquadramentos mais positivos sobre a sua relação com a doença e a valorização do seu contributo para o debate social acerca dessa problemática.

\section{PERCURSO METODOLÓGICO}

Em um primeiro momento, realizamos seis visitas de observação a uma instituição do terceiro setor especializada no tratamento de crianças e adolescentes com câncer em Fortaleza. Nestas, foi possível estabelecer contato com adolescentes, conhecer de forma exploratória os seus hábitos de consumo de mídia e introduzir os temas que iríamos abordar.

$\mathrm{Na}$ segunda fase, realizamos dois grupos focais com um total de oito participantes, que tinham iniciado o tratamento contra o câncer entre 12 e $18 \operatorname{anos}^{1}$. A pesquisa foi realizada na própria instituição que atendia esses adolescentes. Antes de cada grupo focal, aplicamos um questionário para caracterizar os participantes, com perguntas sobre idade, escolaridade, tempo de tratamento na instituição, profissão dos pais e questões relacionadas ao acesso às notícias e aos meios de comunicação.

Os grupos focais são frequentemente utilizados em estudos de recepção e permitem identificar como os participantes compreendem o tema em questão, com base na conversação

\footnotetext{
${ }^{1}$ O projeto desta pesquisa foi submetido ao Comitê de Ética em Pesquisa da Universidade Federal do Ceará (UFC) e ao Comitê de Ética da entidade onde desenvolvemos o trabalho de campo. Para a realização dos grupos focais, todos os participantes voluntários e seus respectivos responsáveis legais assinaram termos de consentimento. Nestes, o compromisso de não divulgar a identidade dos participantes foi assinalado. Por isso, optamos por utilizar nomes fictícios no momento da análise dos grupos focais. O trabalho de campo foi originalmente desenvolvido para a elaboração da monografia de conclusão de curso de Autor (2014) (Os dados de autoria da monografia dados foram extraídos para atender a necessidade de anonimato na submissão do artigo).
}

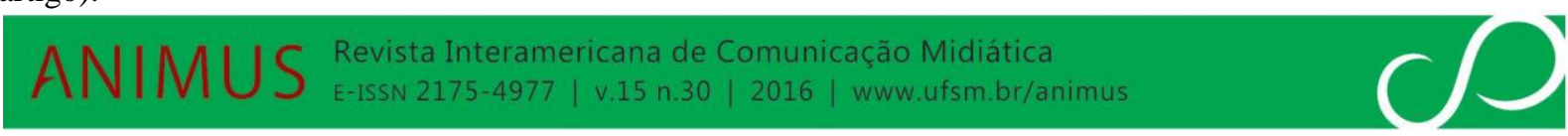


e interação entre eles (HANSEN et al, 1998). A conversa em grupo tem o potencial para fazer os participantes se sentirem mais à vontade diante da experiência compartilhada, criando oportunidade para "falar sobre questões normalmente não levantadas, especialmente se os grupos foram convocados para refletir algum atributo ou experiência em comum que os difere de outros (...)" (BARBOUR, p. 44, 2009).

Constituímos, então, um grupo com quatro meninas e outro com quatro meninos, com o objetivo de enriquecer o corpus da pesquisa e explorar possíveis singularidades nas leituras das notícias associadas ao fator de gênero. Realizamos um encontro com cada grupo, entre os meses de abril e maio de $2014^{2}$. No primeiro grupo focal, contamos com a participação de Carla (13 anos), Joana (15 anos), Patrícia (16 anos) e Isabela (17 anos). No segundo, contamos com a participação de Adam (12 anos), Lucas (15 anos), Leo (16 anos) e Max (20 anos $)^{3}$. Apesar de estarem a enfrentar diferentes estágios da doença, todos ainda estavam em tratamento, por períodos que variavam de dois meses a dois anos e cinco meses. De acordo com as informações fornecidas pelos questionários, os pais desses jovens têm profissões pouco qualificadas (as mães são domésticas ou donas de casa e os pais são caminhoneiros, agricultores, açougueiros, motoristas de ônibus etc.), o que nos permite inferir que suas famílias têm rendas baixas ou médias.

O roteiro dos grupos focais incluiu os seguintes temas: a rotina após o diagnóstico da doença; a exposição às notícias; a experiência em participar como fonte de informação em notícias; a presença de jornalistas e/ou câmeras na instituição; pontos positivos e negativos da cobertura sobre o câncer envolvendo crianças e adolescentes; e a apropriação da cobertura jornalística sobre esta temática.

Utilizamos como material de estímulo, duas notícias exibidas em canais abertos da televisão e um vídeo postado na internet:

- Matéria 1 - Depoimentos - Videocast do Portal TV UOL junto à matéria "Esperança: o câncer não pode ser uma sentença de morte". O vídeo tem duração de cinco minutos e traz depoimentos de adolescentes com câncer sobre os seus sonhos e sobre suas atividades rotineiras. Postado em 4 de fevereiro de 2014;

- Matéria 2 - Celebridades - Notícia exibida no Globo Esporte (local) sobre a visita do elenco da seleção cearense de basquete à instituição onde os adolescente estão em

\footnotetext{
${ }^{2}$ Os grupos focais foram realizados no auditório do hospital onde os adolescentes estavam em tratamento e duraram em média 1 hora e 15 minutos.

${ }^{3} \mathrm{O}$ nome de todos os adolescentes que aparecem neste trabalho são fictícios.
}

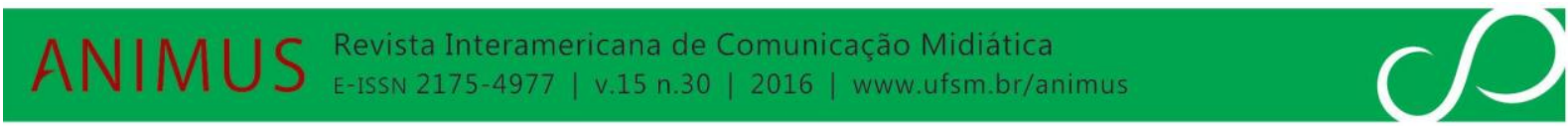


tratamento. Nela, aparecem relatos dos jogadores e sua interação com os meninos e meninas em atendimento. Exibida em 30 de agosto de 2012.

- Matéria 3 - Doações - Matéria do Jornal da Jangadeiro (A TV Jangadeiro é afiliada da Rede Bandeirantes no Ceará) sobre a necessidade da instituição de receber doações para manter suas atividades. Nela, os adolescentes aparecem nos espaços do hospital da instituição, mas não são convocados a falar. Exibida em 23 de agosto.

\section{O QUE DIZEM OS ADOLESCENTES}

Os adolescentes participantes da pesquisa afirmaram, em ambos os grupos (meninos e meninas), ter acesso a notícias por meio de mídias diversas e com níveis de interesses também variados.

As meninas disseram ter a internet como principal meio de informação e que não se interessam muito por TV, enquanto os meninos afirmaram assistir a muitas horas de TV e não acessar tanto a internet. Em relação ao contato com as notícias, as meninas não demonstraram especial interesse, duas delas, inclusive, mencionaram não ter o hábito de ver programas jornalísticos. Em todo caso, as meninas reconheceram que acabam assistindo ao jornal por uma convocação dos pais e/ou quando a matéria traz informações sobre a doença, o que desperta interesse em algumas delas.

Os meninos, por sua vez, valorizaram o discurso noticioso como uma forma de se manterem informados sobre o Brasil e o mundo, em sintonia com os resultados de outras pesquisas em que crianças e adolescentes reconhecem um papel educacional e informativo nas notícias, mesmo sem ser audiência frequente destas (FISCHBERG, 2007; MARÔPO, 2013; ALON-TIROSH e LEMISH, 2014).

O contato direto com notícias sobre o câncer não é frequente, segundo os depoimentos dos participantes da pesquisa. Em relação a notícias específicas sobre a instituição onde os adolescentes recebem tratamento, três das quatro meninas se lembravam de terem visto. Duas delas tinham, inclusive, participado como fonte de informação. Já os meninos não lembraram de nenhuma, embora tenham manifestado inicialmente maior interesse pelas notícias.

Apesar das diferenças nos níveis de contato com as notícias sobre crianças e adolescentes com câncer, meninos e meninas se mostraram interessados e reflexivos no debate sobre a temática. Seus depoimentos refletem, principalmente, preocupações com a vitimização dos doentes e um desejo de enquadramentos mais otimistas, que os valorizem 
como sujeitos participantes das notícias em seus próprios termos e condições. É o que discutiremos a seguir.

\subsection{Vitimização dos doentes}

As falas dos adolescentes expressam uma clara preocupação com a vitimização de crianças e adolescentes com câncer em notícias com foco nas dificuldades do tratamento da doença. Estes enquadramentos mais pessimistas levantam preocupações de três ordens.

A primeira diz respeito à privacidade de quem está a vivenciar momentos de incerteza no tratamento da doença. A publicização de depoimentos de adolescentes centrados nas dificuldades do tratamento tende a gerar sentimentos incômodos e uma inquietação quanto aos constrangimentos que a exibição pública de pessoas nesta situação possa causar.

- Ainda mais mostrar para todo mundo que aquela pessoa tá mal, tá triste, é meio... não sei explicar (Joana, 15 anos).

Por outro lado, esses conteúdos despertam também sentimentos de solidariedade diante do sofrimento do outro, embora a empatia os faça rememorar a insegurança e o medo que marcam as fases mais duras da luta contra a doença.

- Quando a gente vê alguém triste, a gente quer ali, passar força, ajudar. E meio que incomoda, porque a gente não quer ver ninguém assim (Patrícia, 16 anos).

- Deu vontade de entrar na tela e dar um abraço nela e falar que vai dar tudo certo (Lucas, 15 anos) $)^{4}$.

Por último, notícias que destacam as dores do tratamento contra o câncer também levantam questões quanto à promoção de uma visão demasiado fatalista sobre a doença.

- [...] passar pras pessoas que câncer não é uma coisa de outro mundo... (Patrícia, 16 anos)

- Monstruosa. (Joana, 15 anos)

- Que é ruim, claro que é ruim. Mas a gente pode viver, pode-se ter uma vida entendeu? (Patrícia, 16 anos)

Nessa linha, os depoimentos apontam para a necessidade do jornalismo apresentar um enfoque mais humanizado dos adolescentes com câncer, que não reduza a complexidade de suas histórias, nem os retratem sempre como vítimas, respeitando-os em suas singularidades e

\footnotetext{
${ }^{4}$ Os depoimentos fazem referência à exposição de uma jovem que está no estágio inicial da doença e chora muito na Matéria 1 - Depoimentos.
}

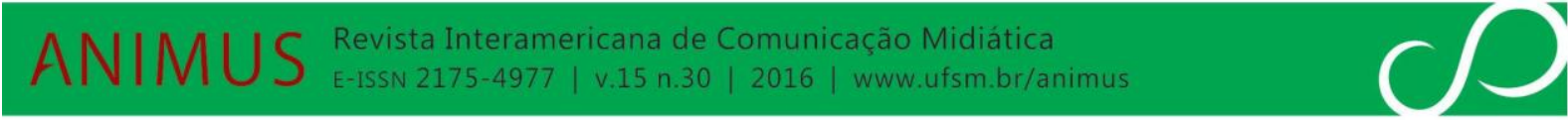


diferenças ${ }^{5}$ e em sua capacidade de superar os desafios que a vida lhes impôs.

Os rapazes trouxeram, com maior ênfase, outra questão sobre a representação de adolescentes com câncer na mídia, que nos chamou atenção: em todas as produções ficcionais sobre adolescentes com câncer que eles conhecem, o paciente morre no final ${ }^{6}$. Esses conteúdos, amplamente divulgados pela mídia, são criticados por serem considerados demasiado pessimistas, não representando integralmente a realidade de adolescentes com câncer, já que eles também convivem com casos de superação e de cura no hospital.

- É, todo filme de histórias que a pessoa tem câncer, no final ela morre.. (.....) Bom, eu acho que eles tentam...eles não passam positividade, eles só passam o lado negativo. Pessoa tá com câncer, vai morrer (Lucas, 15 anos)

- E hoje tem muita história de gente que... sobreviveu e tá aí hoje se divertindo, alegre, aí passa força pra gente, pensa assim...nem liga: Ah, isso aí eu vou tirar de letra. Vai ser só mais um! (Adam, 12 anos).

- É porque eu acho que quando ele vai fazer o livro ele não pensa assim em incentivar, ele pensa mais em deixar o livro dramático (Léo, 16 anos).

Assim, ao terem conhecimento da existência desses filmes e de suas respectivas finalizações trágicas, preferem não ter contato com os mesmos. Além disso, os adolescentes criticam tais produtos pelo endereçamento mercadológico que vislumbra o grande público, sem pensar nos próprios pacientes que estão de alguma forma representados nos personagens dessas histórias.

- Assim, eu acho que é como o Léo falou. Eu acho que eles não procuram agradar as pessoas que estão doentes, incentivar. Eu acho que eles procuram mais agradar a mídia em geral. Fazer um fundo dramático e todo mundo se emociona (Max, 20 anos).

Em seus relatos, os meninos revelam nutrir a expectativa de que, com o jornalismo visto como responsável por divulgar informação "verdadeira e relevante" - poderia ser diferente. Percebe-se isso quando eles afirmam que o final das histórias desses filmes e livros poderia ser outro, caso os produtores tivessem a mesma atitude de um repórter de jornal, em ir ao local antes de criar a história.

- Se eles fossem antes de eles fazerem um filme, ou então um livro, eles fossem num hospital que nem esse aqui, procurassem os adolescentes que tão passando por isso aqui, eu acho que seria diferente. O final do filme, né?

\footnotetext{
5 Mais adiante, abordaremos as diferenças entre os adolescentes na forma de entender o resguardo de sua privacidade, o que evidencia a necessidade do jornalismo considerar a questão da singularidade.

${ }^{6}$ Os adolescentes citaram obras como Uma Prova de Amor (filme de Nick Cassavetes, EUA, 2009), Cartas para Deus (filme de David Nixon, EUA, 2011) e A Culpa é das Estrelas (livro de John Green, 2012).
}

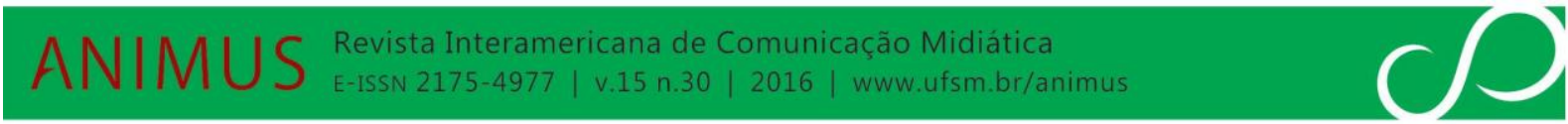


(Max, 20 anos).

De acordo com eles, se fossem como as notícias, os livros e filmes poderiam ter outras abordagens, dissociando o câncer de um destino incontornável como a morte.

Essa perspectiva dos adolescentes remete para um reconhecimento do valor do jornalismo, como discurso verídico, em uma postura que se assemelha ao que Buckingham (2000) identifica como criticismo dos jovens diante das notícias. Em oposição ao ceticismo, que denota um distanciamento e indiferença diante dos acontecimentos e da sua representação noticiosa, o criticismo implica envolvimento emocional e crença de que a verdade sobre os fatos pode e deve ser contada.

$\mathrm{Na}$ perspectiva dos adolescentes, esta verdade passa necessariamente por representações noticiosas mais otimistas da relação dos pacientes com a doença, como veremos a seguir.

\subsection{Representações mais otimistas}

Meninos e meninas apreciam e valorizam quando as notícias não se limitam a abordar o sofrimento causado pela doença, mas, sim, quando estas destacam seus planos para o futuro e aspectos positivos das suas vivências. De acordo com o relato deles, a vida depois da descoberta da doença não consiste apenas nas dores do tratamento, mas também se traduz em novas amizades, vivências amorosas e experiências construtivas, por meio das quais compartilham trajetórias de superação entre pares e amadurecem. Assim, manifestam o anseio de que a mídia e, nesse contexto, o jornalismo, possa promover socialmente uma imagem mais plural de quem luta contra a doença. Afinal, ainda que não tenham o hábito regular de ver notícias, entendem a importância destas na construção do modo como a sociedade os vê.

Neste sentido, as meninas veem as notícias sobre a instituição onde são tratadas como uma oportunidade para a promoção de enquadramentos mais positivos sobre o câncer. A divulgação das ações da instituição permite ao discurso noticioso mostrar que não existem só dificuldades durante o tratamento da doença. É a valorização desta perspectiva que leva as meninas a verem de maneira positiva a possibilidade de participação em notícias cujo foco seja a superação da doença. A ideia delas é servir de estímulo para outros que travam a luta contra o câncer, privilegiando a fase em que já estão curadas ou próximas da cura ${ }^{7}$, quando já estão mais fortalecidas.

\footnotetext{
${ }^{7}$ Algumas também ressalvam que não gostariam de ser identificadas, como veremos mais à frente.

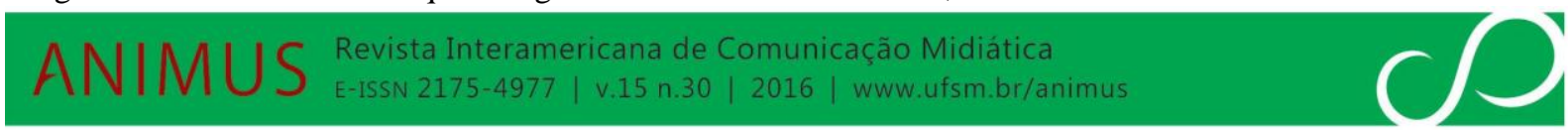


- E eu acho legal mostrar como a gente é bem cuidado aqui, entendeu. Que não é só aquela coisa de injeção e quimioterapia, não. Que também tem o lado carinhoso, da união, entendeu? (Patrícia, 16 anos). ${ }^{8}$

- Eu acho que no começo é mais incomodante falar, do que depois (Joana, 15 anos)

- Quando você tá passando, é meio ruim de falar, né? Mas quando você supera, parece que você tem orgulho de falar. "Ah, eu passei, mas eu tô aqui, tô vencendo..." (Patrícia, 16 anos).

- "Eu tô saindo..." (Joana, 15 anos)

- "Aí tu vai vencer também" (Patrícia, 16 anos).

Os meninos, por sua vez, destacaram que acham interessante quando os adolescentes aparecem de forma espontânea e alegre nas notícias, o que vai ao encontro das suas expectativas de representações mais positivas. Em um comentário sobre a exposição de adolescentes na Matéria 2 - Celebridades, Max (20 anos) ressalta apreciar esse tipo de abordagem:

- Eu achei que foi de forma espontânea, assim, foi bem natural. Eu acho que eles tavam bem à vontade, tavam alegres. Eu achei bacana.

\subsection{A valorização da condição de sujeito}

Ambos os grupos destacaram apreciar bastante quando a matéria privilegia o ponto de vista do adolescente, visto como mais realista e capaz de motivar os pares a lutar contra a doença.

Quando da exibição da Matéria 2 - Celebridades, que enfatizou a ação solidária de celebridades junto à entidade que prestava assistência ao grupo, os adolescentes reconheceram diferenças entre as notícias que dão espaço para que o próprio adolescente fale sobre si mesmo e sobre sua história de superação, e aquelas que conferem aos adultos o papel de analisar a situação pela qual eles estão passando.

No grupo das meninas, elas demarcaram essa diferença explicitamente, afirmando que o próprio paciente estaria mais apto a "passar força" e assim motivar outros adolescentes que estivessem na mesma situação. A matéria, segundo elas, assume uma conotação mais realista se o próprio adolescente tiver a oportunidade de dar o seu relato do que quando um adulto fala por eles.

- Eu acho que assim, porque a da Joana, foi o próprio, o próprio paciente passando força. Já o deles, do basquete, foi um incentivo. Então, para mim,

\footnotetext{
${ }^{8}$ Este depoimento e o seguinte foram dados no contexto da discussão sobre a disponibilidade deles em participar de entrevistas no ambiente do hospital.
}

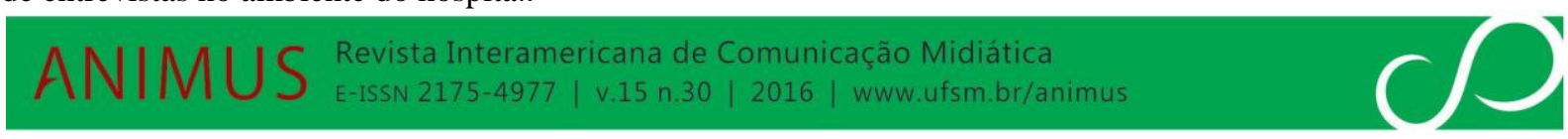


eu acho que há uma grande diferença (....) não que o dela seja melhor, não, porque é fundamental os dois, entendeu? Outras pessoas darem força. Mas a diferença é que quando você tá ali, você tá vivendo, é melhor de passar para outra pessoa. Passar força (Patrícia, 16 anos).

- Porque você sabe, você entende, você sabe o que tá passando. Você sabe explicar melhor do que quem vem visitar. (...) Acho que sai mais realista, digamos assim (Joana, 15 anos).

Ao mesmo tempo, como evidencia o depoimento acima, as meninas consideram valiosas as notícias em que outras pessoas elogiam a "força" que elas têm no enfrentamento da doença. Reconhecem tais discursos como sendo uma forma de incentivo e de reflexão, aplicáveis em suas próprias vidas, ainda que, na visão delas, tais discursos não tenham a mesma potência que os do próprio paciente. Ao comentarem a expressão da celebridade/atleta na Matéria 2, os meninos também a avaliam como importante, por impulsioná-los a relativizar as próprias dificuldades diante dos problemas vivenciados por outras pessoas. No entanto, meninos e meninas são reticentes em se reconhecerem como 'heróis', conforme identificados por um dos jogadores.

\subsection{Os adolescentes e a produção da notícia: a importância da negociação}

Pelo exposto, fica evidente que meninos e meninas apreciam que seus pontos de vista sejam destacados nas notícias e em outros produtos de comunicação sobre o câncer. Ressaltam, contudo, que é fundamental que as condições da sua participação sejam negociadas. Isto implica a necessidade de escuta sobre o seu interesse em participar na matéria, a forma como essa participação pode ocorrer, os limites da exposição de suas imagens e histórias de vida, entre outros.

Ao relatar experiências diversas de contato com profissionais do jornalismo ${ }^{9}$, meninos e meninas exprimiram o desejo de ver preservado o seu direito de optar pela publicização ou não de suas imagens e histórias de vida, questionando as situações em que se viram compelidos a se expor em condições e formas não negociadas diretamente. ${ }^{10}$

Embora dispostas a colaborar como fontes de informação nas notícias, nem todas as adolescentes se mostraram à vontade para expor a sua identidade diante do público.

- Porque... se fosse só pra conversar assim com a pessoa, tudo bem, falaria.

\footnotetext{
${ }^{9}$ Experiências com os funcionários e voluntários da instituição, que fotografavam pacientes, também foram relatadas.

${ }^{10}$ Muitas vezes, a autorização para a publicização dessas imagens é negociada diretamente com familiares e/ou responsáveis institucionais.
}

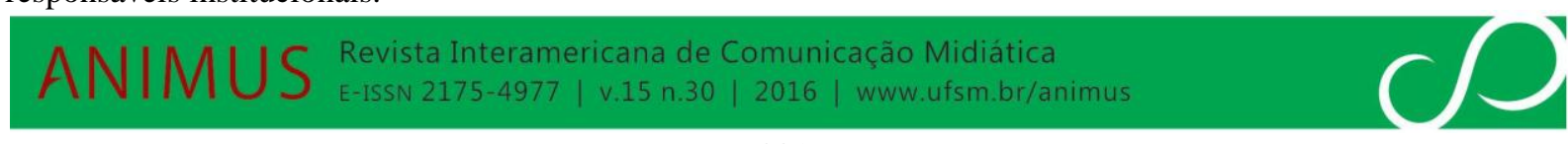


Mas pra mostrar pra todo mundo, não quero também, que todo mundo saiba, né? ... do meu pessoal (Carla, 13 anos)

- É de pessoa para pessoa. Tipo, tem gente que prefere ficar na sua, aqui dentro, quietinho, só esperando...Acho que não quer mostrar para todo mundo o que você passa aqui dentro. Acho que é mais por vergonha mesmo...(Joana, 15 anos).

- Eu, particularmente, eu não falava também por vergonha e porque eu não gosto, assim (baixando o tom de voz) de ficar falando da minha vida pessoal (Isabela, 17 anos).

Face às reportagens em que os adolescentes apenas aparecem nos espaços do hospital, como forma de ilustrar o trabalho da instituição, mas não são convocados a falar, como na Matéria 3 - Doações, as meninas expressaram se reconhecer como parte da própria instituição. Ao comentarem a necessidade de a entidade receber doações, elas também se veem como parte desta, usando a expressão "a gente" para falar delas e do hospital. Certamente, esse entendimento contribui para que vejam de forma a-problemática o uso de suas imagens em notícias que dão visibilidade às boas ações da entidade.

- [...] realmente a gente precisa de ajuda, né? Das doações, pra seguir em frente (Patrícia, 16 anos).

Já os meninos, muitos dos quais ainda não passaram por uma experiência assim, aproveitaram o momento da discussão para lamentar situações ocorridas na própria instituição, em que os seus direitos, relativos ao uso de suas imagens e à privacidade, não foram respeitados. Os adolescentes alegaram se sentir sem opção, quando, eventualmente, viam-se obrigados a posar para fotografias mesmo contra a vontade.

- Eu também acho, assim, normal [ser filmado por câmera]. Mas, assim, eu acho assim, esse caso de tirar foto, essas coisas, eu acho que quem vai tirar, eu acho que tem que vir perguntar primeiro, assim. Porque que nem ele falou, algumas pessoas ficam intimidadas, não gostam, né? $\mathrm{E}$ fica chato, né? Você lá, meio com vergonha, o cara tirando foto (Max, 20 anos).

- Tipo, naquele dia que tava eu, tu e o Daniel, o cara: "Ó, você senta aqui, bora tirar foto". Ele nem perguntou se a gente queria (Lucas, 15 anos).

- Bom, às vezes, a gente não quer, né? mas... o que é a gente, né? As pessoas chegam e batem a foto (Lucas, 15 anos).

- Não tem opção, né? (Max, 20 anos)

- Não tem opção. Eles chegam e batem, na cara de pau (Lucas, 15 anos).

Estes depoimentos evidenciam que, apesar da nobreza de propósitos de campanhas institucionais voltadas para promover o debate sobre a doença na sociedade, cobrar providências do poder público e/ou angariar recursos, a gestão da imagem desses adolescentes 
nem sempre tem sido feita com a atenção necessária.

As meninas, por sua vez, valorizaram experiências com alguns jornalistas que solicitaram devidamente a entrevista e pediram a autorização delas antes de publicar a matéria. Esse foi o caso de Joana (15 anos) que, embora reconhecendo ter ficado inicialmente constrangida com a presença da câmera, superou esse sentimento, pois além de receber as explicações iniciais sobre o que seria o vídeo, tranquilizou-se com o modo como o réporter posicionou discretamente a câmera, favorecendo um ambiente de conversa, apresentando-lhe, ainda, o conteúdo do vídeo antes de publicá-lo ${ }^{11}$.

- Eu fui uma das primeiras pessoas a ver. Perguntou se tava legal, se eu gostei, eu disse "gostei", que podia postar (Joana, 15 anos).

Este relato evidencia a importância dos jornalistas (e demais profissionais da comunicação) humanizarem a relação com as crianças e adolescentes como fontes de informação sobre o câncer, considerando a singularidade de cada um nesse processo e os seus direitos à privacidade.

\section{CONSIDERAÇÕES FINAIS}

Embora não demonstrem especial interesse pelas notícias, os meninos e meninas participantes desta pesquisa estão expostos a conteúdos noticiosos em diferentes mídias. As notícias que abordam o câncer e representam crianças e jovens como doentes despertaram nos participantes da pesquisa atitudes próximas do que Buckingham (2000) identificou como criticismo, o que implica uma atitude reflexiva, baseada no envolvimento emocional com o discurso noticioso e na valorização do jornalismo como um discurso supostamente verídico.

Neste sentido, com base nos depoimentos dos adolescentes, podemos inferir inúmeras sugestões para que o jornalismo aborde, de uma maneira mais acurada, os desafios de quem enfrenta uma doença como o câncer.

Primeiramente, extraímos uma sinalização clara no sentido de que o jornalismo desenvolva uma escuta sensível das experiências dos adolescentes, de modo a não reduzir a complexidade de suas vivências à condição de vítimas da doença. Para os meninos, o

\footnotetext{
${ }^{11}$ Mostrar o produto final da notícia para a fonte antes de publicá-la é uma questão polêmica no jornalismo. Mas, no contexto aqui apresentado, em que o profissional está lidando com adolescentes em uma situação peculiar de fragilidade física, consideramos tratar-se de uma situação excepcional, em que esta atitude pode demonstrar o cuidado e a sensibilidade que uma circunstância como essa exige.
}

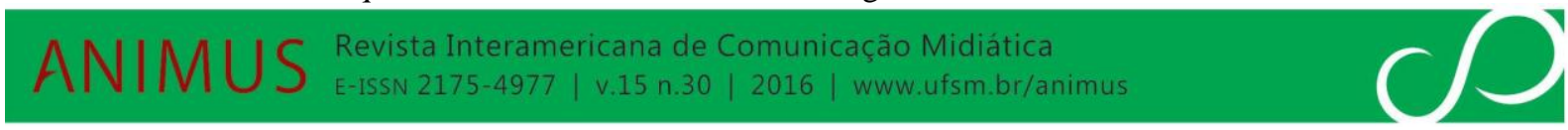


jornalismo tem mais credibilidade do que as representações fatalistas do cinema, entre outras. Por isso mesmo, poderiam (e deveriam) ouvir os adolescentes para perceber que, muitas vezes, eles podem ser bem sucedidos no combate ao câncer.

De forma complementar, os adolescentes sugerem também outros enquadramentos para a cobertura jornalística que destaque não só as dores durante o tratamento da doença, mas também alegria, cumplicidade, companheirismo, aprendizado e amadurecimento, trazendo um tom mais otimista às matérias.

Para os adolescentes, suas conquistas no enfrentamento da doença não decorrem apenas do amparo dos adultos, mas também do seu empenho em superar os desafios. Nesse sentido, não querem ser representados apenas como objeto da atenção e de cuidados de adultos e das instituições que os acolhem, por mais que os vejam como parceiros fundamentais no enfrentamento da doença, a demanda deles é para serem reconhecidos em sua condição de sujeitos na luta pela vida. Neste sentido, valorizam a visibilidade dos seus pontos de vista no discurso noticioso e também no discurso promocional das instituições de tratamento onde fazem tratamento. Esta visibilidade é percebida como uma oportunidade para se exprimirem publicamente sobre um tema que lhes diz diretamente respeito e também como um contributo válido para o debate social. Enquanto os meninos destacam a importância da espontaneidade no modo como os adolescentes se apresentam, as meninas afirmam que a voz dos adolescentes com câncer é útil para motivar outros a lutarem contra a doença, para explicar melhor o que é viver com a enfermidade e para dar mais "realismo" à notícia.

No entanto, meninos e meninas questionam situações em que as suas imagens são utilizadas sem que sejam consultados sobre como se sentem em relação à sua exposição e de suas vivências pessoais. Neste sentido, é necessário reforçar as orientações aos jornalistas (válidas também para profissionais de outras áreas da comunicação) para que discutam com as crianças e adolescentes as possíveis consequências negativas das notícias e obtenham destes e de seus responsáveis o consentimento informado (UNICEF/MEDIA WISE, 2010; SAVE THE CHILDREN, 1998, ANDI, 2009).

As meninas demonstram um maior envolvimento emocional com a instituição e se mostram bastante disponíveis para utilizar a própria imagem em campanhas para angariar verbas. No entanto, referem a importância de se respeitar as singularidades de cada adolescente no que concerne à sua identificação pública, seja nas notícias ou em campanhas institucionais. No mesmo sentido, os meninos condenam situações em que foram impelidos a serem fotografados na instituição sem o seu consentimento informado. 
Em resumo, os adolescentes reconhecem a capacidade do jornalismo de esclarecer a sociedade sobre o câncer e para alertar sobre as necessidades de tratamento da doença. Por outro lado, seus depoimentos apontam para o desafio do discurso noticioso (e também do discurso promocional) de promover uma imagem dos doentes como sujeitos ativos, por meio da inclusão do seu ponto de vista no debate público, garantindo, ao mesmo tempo, o seu consentimento informado quanto à divulgação da sua imagem e identidade. Em outras palavras, nos termos de Dahlgren (2009), trata-se do reconhecimento dos jovens como cidadãos, sendo a ação destes uma condição central para a construção das suas identidades cívicas.

\section{REFERÊNCIAS}

AL-GHABBAN, A. Global viewing in East London: multi-ethnic youth responses to television news. In: European Journal of Cultural Studies. Vol. 10, p. 311, 2007.

ALON-TIROSH, M. e LEMISH, D. "If I was making the news": What do children want from news? In: Participations - Journal of Audience \& Reception Studies, v. 11, $\mathrm{n}^{\circ}$ 1, p. 108129. 2014

ANDI/Rede ANDI. Mais janela que espelho: a percepção de adolescentes com deficiência sobre os meios de comunicação na Argentina, no Brasil e no Paraguai. Brasília: ANDI. 2008

ANDI. Estatuto da Criança e do Adolescente - Um Guia para Jornalistas. Rede ANDI Brasil: Belo Horizonte (MG), 2009.

BARBOUR, R. Grupos Focais. Porto Alegre: Artmed, 2009.

BRITES, M. J. Jovens e culturas cívicas: Por entre formas de consumo noticioso e de participação. Covilhã: Livros LabCom. 2015

BUCKINGHAM, D. The Making of Citizens: Young People, News and Politics. Londres: Routledge. 2000.

As crianças e a mídia: uma abordagem sob a ótica dos Estudos Culturais. Revista Matrizes, vol. 5, nº 2, p. 93-121. 2012.

CANCLINI, N. G. Culturas Híbridas: estratégias para entrar e sair da modernidades. São Paulo: EDUSP. 2008

CARVALHO, M. J. L.; SERRÃO, J. A voz de jovens em instituição (sistema tutelar educativo): percepção e representações de jovens dos centros educativos sobre os media. In C. Ponte (ed.). In: Crianças e Jovens em Notícia. Lisboa: Livros Horizonte. 2009.

CORREIA, J. C. Comunicação e Cidadania: Os Media e a Fragmentação do Espaço ANIMUS Revista Interamericana de Comunicação Midiática 
Público. Lisboa: Livros Horizonte. 2004

DAHLGREN, P. Media and Political Engagement: Citizens, Communication, and Democracy. University Press: Cambridge. 2009.

DELORME, M. I. Domingo é Dia de Felicidade: as crianças e as notícias. Rio de Janeiro: Editora Multifoco. 2012.

FISCHBERG, J. Criança e jornalismo: um estudo sobre as relações entre crianças e mídia impressa especializada infantil. Dissertação de Mestrado do Programa de Pós-Graduação em Educação, Pontifícia Universidade Católica do Rio de Janeiro. 2007.

HALL, S. et AL. Policing the crises - Mugging, the state, the law and order. Nova Iorque: Palgrave Mcmillan. 1978.

HANSEN et al. Mass Communication Research Methods. Nova York: Palgrave. 1998.

MARÔPO, L.; GOMES, L. A. Construindo sentidos com base nas notícias: um estudo de caso com adolescentes num bairro brasileiro de baixo rendimento. In: II Congresso Media, Literacia e Cidadania, 2013, Lisboa. Livro de Atas do 2. ${ }^{\circ}$ Congresso Literacia, Media e Cidadania, p. 286-250. 2014.

MARÔPO, L. Identidade e estigmatização: as notícias na perceção de crianças e jovens de um bairro de realojamento. In: Análise Social, v. XLIX, p. 104-127, 2014.

MARTÍN-BARBERO, J. América Latina e os anos recentes: o estudo de recepção em comunicação social. In: SOUZA, M. W. Sujeito, o lado oculto do receptor. São Paulo: Brasiliense. 1995.

SAVE THE CHILDREN/McCRUM S., HUGHES, L. Interviewing Children - A Guide for Journalists and Others. Save the Children: London. 1998.

THOMPSON, J. B. Ideologia e cultura moderna: teoria social crítica na era dos meios de comunicação de massa. Petrópolis: Vozes. 2007.

UNICEF, MEDIAWISE. The Media and Children's Rights - A Resource for Journalists by Journalists. Unicef and Mediawise: Geneva. 2010.

WOODWARD, K. Identity and Diference - Culture, Media and Identities, Londres: Sage Publications Open University. 1997.

Original recebido em: 21-08-2015

Aceito para publicação em: 10-05-2016

Raiana de Carvalho

Graduada em Comunicação Social - Jornalismo pela Universidade Federal do Ceará (UFC). 
Atua como jornalista e como pesquisadora do Grupo de Pesquisa da Relação Infância, Juventude e Mídia (Grim) da UFC.

Inês Vitorino Sampaio

Doutora em Ciências Sociais pela Universidade Estadual de Campinas (1999), com período sanduíche na Westfälische Wilhelms Universität Münster, Alemanha. Em 2008, realizou estágio Pós-Doutoral na Université du Québec à Montréal, UQÀM, Canadá (2008). É Vicediretora e Coordenadora Acadêmica do Instituto de Cultura e Arte da Universidade Federal do Ceará (gestão 2011-2015). Coordenou o projeto de implantacão do Programa de Pós-

Graduação em Comunicação da UFC, no qual é docente vinculada à linha de mídias e práticas socioculturais. Foi vice-presidente da Associação Nacional de Pós-Graduação em

Comunicação - Compós (biênio 2014-2015), tendo sido secretária-geral no biênio 20112013. É autora do livro Televisão, Publicidade e Infância (Annablume, 2004), co-autora do livro Qualidade na Programação Infantil na TV Brasil (Ed.Insular, 2012), tendo ainda organizado as coletâneas Mídia de Chocolate: estudos sobre a relação infância, adolescência e comunicação (E-papers, 2006) e Comunicação, Cultura e Cidadania (2012), além de ter

publicado dezenas de artigos em periódicos da área. Coordena o Grupo de Pesquisa da Relação Infância, Juventude e Mídia (GRIM - Núcleo UFC) e o Projeto de Extensão TVez: Educação para o uso crítico da mídia.

Lídia Marôpo

Lidia Marôpo é professora Adjunta no Instituto Politécnico de Setúbal (Portugal). É também investigadora integrada no Centro Interdisciplinar de Ciências Sociais (CICS.Nova),

Universidade Nova de Lisboa, onde desenvolveu sua investigação de pós-doutoramento financiada pela Fundação para a Ciência e a Tecnologia de Portugal (FCT). É graduada em Comunicação Social - Jornalismo - pela Universidade Federal do Ceará (Brasil), mestre em Ciências da Comunicação - Estudo dos Media e do Jornalismo - e doutorada em Ciências da

Comunicação pela Faculdade de Ciências Sociais e Humanas da Universidade Nova de Lisboa. É autora dos livros "A construção da Agenda Midiática da Infância" (Livros Horizontes, 2008) e "Jornalismo e Direitos da Criança - Conflitos e Oportunidades em Portugal e no Brasil" (Editora MinervaCoimbra, 2013). Atuou como jornalista profissional no Brasil e como jornalista colaboradora em Portugal. Foi convidada para ministrar formação para jornalistas e fontes de informação sobre jornalismo e direitos da criança em Portugal (Cenjor), Brasil (Cedeca/Unicef), Moçambique (Unicef) e Irlanda (Unicef/Dublin Institute of Technology, para jornalistas da Europa de Leste e da Ásia).

Esta obra está licenciada sob uma Licença Creative Commons.

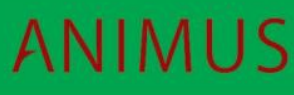

